\title{
A suspensão do Paraguai no MERCOSUL: problema interno, solução externa ${ }^{1}$
}

The suspension of Paraguay in MERCOSUL: internal problem, external solution

Guilherme Frizzera²

\section{RESUMO}

O Paraguai foi suspenso do MERCOSUL após o impeachment do Presidente Fernando Lugo. Como consequência, o último empecilho para a inclusão da Venezuela no bloco - a aprovação por parte do Senado paraguaio - foi superado. A condicionante imposta para o retorno do Paraguai ao bloco é reconhecer a Venezuela como membro. Suspenso por um problema interno, o retorno está sujeito a uma solução externa.

Palavras-Chave: Paraguai; MERCOSUL; Venezuela.

\begin{abstract}
Paraguay was suspended from MERCOSUR after the impeachment of President Fernando Lugo. As a result, the last obstacle to the inclusion of Venezuela on the block - approval by the Paraguayan Senate - was overcome. The condition imposed for the return of Paraguay to the block is to recognize Venezuela as a member. Suspended by an internal problem, the return is subject to an external solution.
\end{abstract}

Keywords: Paraguay; MERCOSUR; Venezuela.

Em 22 de junho de 2012, o então Presidente paraguaio Fernando Lugo foi destituído de seu cargo. Desde o processo de impeachment, o Paraguai sofreu um processo de suspensão como membro do MERCOSUL. Após a suspensão do Paraguai, o MERCOSUL efetivou a entrada da Venezuela como membro permanente do bloco regional. No entanto, por se tratar de um membro permanente do MERCOSUL, o Congresso paraguaio deveria aprovar a entrada da Venezuela no bloco, mas a organização passou por cima de suas próprias regras. Com a entrada de um novo governo, iniciou-se uma movimentação para a reintegração do Paraguai no MERCOSUL.

\footnotetext{
${ }^{1}$ Artigo recebido em 28 de agosto de 2013 e aprovado para publicação em 02 de outubro de 2013.

${ }^{2}$ Graduado em Relações Internacionais pelas Faculdades Integradas Rio Branco. Mestrando em Integração da América Latina pela Universidade de São Paulo (PROLAM/USP). São Paulo, Brasil.
} 
Não obstante, indícios apontam que, para ser reintegrado, o governo paraguaio deve reconhecer a Venezuela como um membro da organização, levando a questão a ser tratada como prioridade da agenda, tanto do MERCOSUL quanto do novo governo do Paraguai.

\section{0 caso paraguaio}

O Paraguai foi suspenso do MERCOSUL, devido à alegação de que o país tinha ferido a cláusula democrática reiterada pelos países do bloco, o denominado Protocolo de Montevidéu, onde consta que os países membros se comprometem a proteger a ordem democrática:

Reiterando o compromisso com a promoção, defesa e proteção da ordem democrática, do estado de direito e suas instituições, dos direitos humanos e as liberdades fundamentais, como condições essenciais e indispensáveis para o desenvolvimento do processo de integração e para a participação no MERCOSUL (MERCOSUL, 2011).

Dentre as alternativas que podem ser adotadas em caso de ruptura democrática, o artigo 6ํำ do protocolo ${ }^{3}$ prevê a suspensão do país membro, revogando o seu direito de participar dos órgãos estruturais que compõem a organização. Portanto, as medidas tomadas pelo MERCOSUL foram, sim, de encontro a algo previsto em seus tratados. Entretanto, em nenhum momento chegou-se a uma definição do que é democracia para a organização. As cláusulas existentes no Protocolo de Montevidéu não apresentam uma definição do que é democracia, apenas apontam medidas que devem ser adotadas caso algum país rompa com a ordem democrática. Desse modo, tende-se a criar conceitos ad hoc do que seria ordem democrática. Cada país define o que é democracia para ele, uma vez que é inexistente uma definição clara do que é ordem democrática para o bloco.

Analisando o caso paraguaio, vê-se que o impeachment do então Presidente Fernando Lugo foi constitucional, pois a Constituição do Paraguai prevê, sim, o impedimento absoluto do chefe de Estado e Governo por "mau exercício das funções"4,

\footnotetext{
${ }^{3}$ Para mais detalhes sobre as medidas que podem ser adotadas em caso de rompimento democrático no MERCOSUL, acesse http://www.mercosur.int/innovaportal/file/4002/1/dec_0272011_pt_ferr_protocolo_de_montevideu_ushuaia_ii.pdf Acesso: 02/09/2013

4 “Artículo 225. El Presidente de la República, el Vicepresidente, los ministros del Poder Ejecutivo, los ministros de la Corte Suprema de Justicia, el Fiscal General del Estado, el Defensor del
} 
sendo esta a justificativa para o processo de impeachment de Lugo. Acrescenta-se, ainda, que a Constituição paraguaia não determina, em nenhum momento, um prazo temporal mínimo para a análise do processo de impeachment. Além disso, a Constituição do país é clara em definir o processo de impeachment como um julgamento político, não salvaguardando os mesmos direitos para o "réu" de um julgamento comum. É impossível afirmar que tenha ocorrido um golpe se o processo está previsto na Constituição.

Na verdade, a Carta Magna apenas garante o direito de defesa do acusado, os procedimentos que devem ser tomados pelo Congresso, a quantidade de votos necessários para a deposição e quem assumirá o cargo na ausência do Presidente. Mas, em nenhum momento, a Constituição garante um prazo mínimo para que a ação ocorra no Congresso e nem ao menos exemplifica o que configuraria o mau exercício da função (CONSTITUIÇÃO DO PARAGUAI, 1992). Portanto, se o MERCOSUL não define o que é democracia para a organização e o Paraguai seguiu estritamente a letra da Carta Magna, o caso já se torna emblemático e suscetível à discussão.

\section{A suspensão do Paraguai}

Imediatamente após o impeachment, assume a presidência do Paraguai o então Vice-Presidente Federico Franco. O MERCOSUL reuniu-se e suspendeu o Paraguai de seus exercícios como membro da organização até abril de 2013, quando novas eleições presidenciais ocorreriam. Além disso, aproveitando que o Congresso paraguaio seria o último obstáculo para a entrada da Venezuela no bloco, ratificou-se a entrada do país como membro efetivo, uma vez que os congressos dos demais membros - Brasil, Uruguai e Argentina - já haviam ratificado a entrada da Venezuela no MERCOSUL (O GLOBO, 24/06/2012).

Mesmo suspenso, o Senado paraguaio votou e rejeitou a entrada da Venezuela no bloco em 23 de agosto de 2012 (FOLHA DE S. PAULO, 23/08/2012). Ressalta-se que a votação ocorreu porque os congressistas paraguaios entenderam que continuavam

Pueblo, el Contralor General de la República, el Subcontralor y los integrantes del Tribunal Superior de Justicia Electoral, sólo podrán ser sometidos a juicio político por mal desempeño de sus funciones, por delitos cometidos en el ejercicio de sus cargos o por delitos comunes". 
membros do MERCOSUL e que, sim, a Venezuela deveria ser aprovada pelo Congresso do Paraguai para se tornar membro permanente da organização. Não obstante, destaca-se que, mesmo sendo rejeitado pela maioria absoluta, muitos congressistas levaram a discussão para a questão comercial, levando em conta que tal atitude poderia causar atritos em futuros negócios com a Argentina e o Brasil. Por outro lado, congressistas também afirmaram que se tratava de uma questão de respeito ao Paraguai e que a medida deveria ser tomada para demonstrar soberania, além da manutenção da ordem vigente (FOLHA DE S. PAULO, 23/08/2012).

Em julho de 2012, o Paraguai entrou com um pedido no Tribunal do MERCOSUL contra a suspensão. 0 pedido foi negado, argumentando-se que tal processo não possuía características de urgência e que o país deveria entrar com um protocolo formal de reclamação, tornando-se mais burocrático e demorado (G1.com, 22/07/2012). Após a rejeição do pedido, o então Presidente Federico Franco afirmou que muitos empresários pediram que o Paraguai abandonasse o MERCOSUL.

Portanto, o Paraguai foi suspenso por uma questão interna - o impeachment do Presidente Fernando Lugo, pois os demais membros do MERCOSUL afirmaram que ele não teve suas garantias constitucionais respeitadas, causando, assim, um rompimento na ordem democrática do país. Com isso, os países membros adotaram uma medida prevista em tratados de suspender o Paraguai e, aproveitando a sua suspensão, tornaram a Venezuela um membro permanente do bloco.

\section{O novo governo paraguaio e as relações com o MERCOSUL}

Após as eleições de abril de 2013, foi eleito para o executivo paraguaio Horácio Cartes. O novo Presidente eleito afirmou que rejeitava o retorno de seu país ao MERCOSUL, baseando-se no argumento que a entrada da Venezuela desrespeitava as normas legais para a entrada no bloco. Segundo Cartes, "o mero transcurso do tempo ou decisões políticas posteriores não restabelecem, por si só, o império do direito. 0 direito internacional e nacional deve ser reconhecido, respeitado e cumprido, tal como foi estabelecido" (UOL, 12/07/2013). Acrescenta-se, ainda, o fato de que o MERCOSUL havia afirmado que o Paraguai seria reintegrado ao bloco no dia 15 de agosto de 2013, 
no mesmo dia da posse de Cartes. Porém, a reintegração do Paraguai está condicionada ao reconhecimento da Venezuela como membro da organização.

Segundo reportagem da Folha de S. Paulo, a avaliação de integrantes do governo brasileiro é que o Paraguai só deveria retornar ao MERCOSUL após análise por parte dos países que integram o grupo econômico e aprovação da adesão da Venezuela ao bloco pelo Congresso de lá. Acrescenta-se, ainda, aguardar o resultado da eleição do Senado para então avaliar se haverá maioria simpática à votação (FOLHA DE S. PAULO, 22/04/2013).

Durante o período entre a eleição até a posse de Horácio Cartes, os discursos do então Presidente eleito apontavam para uma ruptura completa do país com a organização ou uma reintegração do país ao bloco, desde que revista a argumentação que gerou a suspensão paraguaia e até mesmo conceder ao país a presidência pro tempore do MERCOSUL. Do outro lado, ao fixar a data de retorno do país ao bloco no mesmo dia da posse do Presidente eleito, o discurso brasileiro - refletido em declarações do então Ministro das Relações Exteriores Antônio Patriota - seria de que as declarações do novo governo eleito do Paraguai ainda refletiam o clima eleitoral, aguardando a sua posse para detectar uma mudança na postura discursiva do país em relação ao MERCOSUL (VALOR ECONÔMICO, 15/07/2013).

Como Presidente de fato, Horácio Cartes alterou sua postura em relação ao bloco sul-americano, adotando um discurso de que o Paraguai teria, sim, interesse em retornar ao MERCOSUL. Porém, o governo continua afirmando que passaram por cima das normas do bloco, uma vez que seus tratados constitutivos preveem a adesão de um novo membro após aprovação por todos os congressos nacionais dos países que integram o MERCOSUL permanentemente (EXAME, 16/08/2013). Cartes deixa claro que não tem nenhum problema com a Venezuela e que a questão está restrita à esfera jurídica e não política. O Presidente paraguaio reitera que o retorno do Paraguai ao MERCOSUL está condicionado à resolução, pelos ministros das Relações Exteriores, do problema jurídico gerado com a incorporação da Venezuela e sem a presença paraguaia (EXAME, 16/08/2013).

Logo, o discurso do novo governo paraguaio aponta que o país deve se reintegrar ao bloco, porém exige uma solução jurídica para o que levou à sua suspensão e à 
aceitação da Venezuela como membro. O Paraguai está condicionado a retornar após o reconhecimento da Venezuela como membro permanente do bloco, ou seja, a solução para a reincorporação do país está em um caso externo. Configura-se, portanto, que o Paraguai foi suspenso por uma ação interna e sua condicionante para o fim da suspensão está em uma ação externa.

\section{O futuro do Paraguai no MERCOSUL e o papel das normas nas relações internacionais}

A inclusão da Venezuela no momento em que o Paraguai estava suspenso criou um oportunismo dos demais membros em incluir um importante parceiro comercial na organização. 0 custo dessa inclusão é que o MERCOSUL tornou-se uma organização institucionalmente mais fraca. Por se tratar de uma organização com funções de integrar os países sul-americanos, ela tem de se firmar sobre as normas que cria. Lembrando que uma das funções das normas positivas é constranger ou regular as ações dos atores. Dado que os Estados são parcialmente constituídos por normas internacionais, eles estão condicionados a agir de maneira particular e suas ações são limitadas por mais variáveis, além do simples cálculo de poder.

Os Estados estão inseridos em uma teia normativa cada vez mais densa, que restringe sua atuação no âmbito externo. Como em toda sociedade, a sociedade internacional é "governada por regras" e a legitimidade é obtida agindo de acordo com as regras. Não havendo normas claras ou sendo elas fracas e desrespeitadas, sua legitimação vai sendo minada com a ocorrência de casos semelhantes. As normas são expectativas coletivas sobre o comportamento adequado para uma determinada identidade. Às vezes, as normas funcionam como regras que definem (e constituem) uma identidade. Além disso, a sociedade internacional é fundada no entendimento coletivo dos Estados do que constitui um comportamento apropriado.

As normas exercem três funções particulares dentro da sociedade internacional. Primeiramente, as normas ajudam a constituir os atores. A existência e a atuação dos Estados na sociedade internacional estão baseadas em duas facetas de soberania. A primeira remete-se à chamada "soberania positiva". A soberania positiva pode ser 
entendida como a habilidade do Estado de assegurar e garantir a legitimidade do monopólio do uso da violência e em fazer cumprir as leis jurídicas dentro de seu território. O segundo aspecto denomina-se "soberania negativa" e refere-se ao reconhecimento de um Estado como uma unidade autônoma e soberana pelos demais membros da sociedade internacional. Portanto, nessa primeira função, as normas internacionais contribuem para constituir os atores na sociedade internacional, tanto por identificar quem são os atores, quanto por conferir direitos e responsabilidades a eles (ADLER; BARNETT, 1998).

A segunda função das normas está no papel de constranger ou regular as ações dos atores. Dado que os Estados são parcialmente constituídos por normas internacionais, eles estão condicionados a agir de maneira particular e suas ações são limitadas por mais variáveis, além do simples cálculo de poder. Os Estados estão inseridos em uma teia normativa cada vez mais densa que restringe sua atuação no âmbito externo (BELLAMY, 2004). Como em toda sociedade, a sociedade internacional é "governada por regras" e a legitimidade é obtida agindo de acordo com as regras (ADLER; BARNETT, 1998).

Por fim, as normas fornecem uma significativa estrutura para comunicação entre os atores da sociedade internacional. As normas criam uma linguagem significativa da sociedade internacional baseada em padrões estabelecidos por meio da interação social. As normas apresentam um quadro da forma como os Estados justificam o seu comportamento e fornecem um meio para a sociedade internacional avaliar suas ações. Quando procuram justificar um ato, os Estados "recorrem às normas". Quando um ator quebra alguma norma, suas ações acabam sendo justificadas em termos de outras normas. (ADLER; BARNETT, 1998; BELLAMY, 2004).

O Paraguai deve retornar ao bloco no final de 2013 ou em 2014, provavelmente após a Venezuela deixar a presidência pro tempore do MERCOSUL. Não compensa para o Paraguai ficar de fora do bloco, visto que $25 \%$ de suas exportações são para os seus colegas de MERCOSUL (EXAME, 16/08/2013). Somam-se a isso os discursos do atual Presidente paraguaio, nos quais afirma que a situação do Paraguai é puramente jurídica e não política. Como ele mesmo afirma, as relações do Paraguai são de "casamento" com atores importantes da região, como o Brasil (EXAME, 16/08/2013). 0 comércio é uma 
variável que supera qualquer divergência política que possa ocorrer no MERCOSUL. Foca-se em questões econômicas, não se buscando uma normatização da conduta política de seus membros. Essa fraca, ou até mesmo ausência, de parâmetros claros do que é entendido como democracia para o bloco (ou mesmo o que é ruptura democrática) torna suas ações oportunistas, isto é, a democracia quando é conveniente.

Ao condicionar o retorno paraguaio ao MERCOSUL por meio do reconhecimento da Venezuela no bloco, demonstra que nem ao menos um órgão soberano como o Senado do Paraguai está sendo respeitado pelos demais membros da organização. Somado a isso, autoridades sugerem a espera de uma nova configuração de senadores para verificar se serão simpáticos à Venezuela. Procura-se essa justificativa para a reincorporação do Paraguai, para que não se apresente uma solução jurídica adequada (e exigida pelo Paraguai) ao problema criado com a incorporação de um novo membro no bloco. Devido à sua fraca normatização e ao comportamento oportunista de seus membros, o MERCOSUL não consegue se aprofundar institucionalmente, tornando a integração sul-americana menos propensa em almejar uma união política de seus membros ou uma normatização clara e comum da organização.

\section{Referências Bibliográficas}

ADLER, Emmanuel; BARNETT, Michael. Security Community. Cambridge University Press: Cambridge, 1998.

BELLAMY, Alex. Security Communities and their Neighbours: Regional Fortresses or Global Integrators? Palgrave Macmillan: New York, 2004.

EXAME. Paraguai aceita Venezuela no Mercosul, diz Cartes. 16/08/2013. Disponível em: exame.abril.com.br/noticia/paraguai-aceita-venezuela-no-mercosul-diz-cartes/ Acesso: 21/08/2013

FOLHA DE S. PAULO. Senado do Paraguai rejeita entrada da Venezuela no Mercosul. 23/08/2012. Disponível em: http://www1.folha.uol.com.br/mundo/1142028senado-do-paraguai-rejeita-entrada-da-venezuela-nomercosul.shtml Acesso: $28 / 08 / 2013$ 
FOLHA DE S. PAULO. Brasil condiciona volta do Paraguai ao Mercosul à entrada da Venezuela no bloco. 22/04/2013. Disponível em: http://www1.folha.uol.com.br/mundo/2013/04/1266682-brasil-condiciona-voltado-paraguai-a-entrada-davenezuela-no-mercosul.shtml Acesso: 20/08/2013

G1.com. Tribunal do Mercosul rechaça pedido do Paraguai de cancelar suspensão. 22/07/2012. Disponível em: g1.globo.com/mundo/noticia/2012/07/tribunal-domercosul-rechaca-pedido-do-paraguai-por-sancoes-1.html Acesso: 22/08/2013.

MERCOSUL. Protocolo de Montevidéu. 20 de dezembro de 2011.

O Globo. Paraguai será afastado do Mercosul e da Unasul até eleições presidenciais em 2013. 24/06/2012. Disponível em http://oglobo.globo.com/mundo/paraguai-seraafastado-do-mercosul-da-unasul-ate-eleicoes-presidenciais-em-2013-5301933 Acesso: 02/10/2013

PARAGUAI. Constituição (1992). Constitución de la República de Paraguay. Junho, 1992.

UOL. Presidente eleito do Paraguai rejeita volta ao Mercosul. 12/07/2013. Disponível em: noticias.uol.com.br/ultimas-noticias/afp/2013/07/12/presidente-eleito-doparaguai-rejeita-volta-ao-mercosul.htm Acesso: 23/08/2013

Valor. Retorno do Paraguai ao Mercosul pode ser revisto, diz Patriota. 15/07/2013. Disponível em: http://www.valor.com.br/brasil/3198956/retorno-do-paraguai-aomercosul-pode-ser-revisto-diz-patriota Acesso: 24/08/2013. 